\title{
Prevalence and factors associated with alterations of the temporomandibular joint in institutionalized elderly
}

\author{
Prevalência e fatores associados a alterações \\ na articulação temporomandibular em idosos institucionalizados
}

\author{
Annie Karoline Bezerra de Medeiros ${ }^{1}$ \\ Fernanda Pinheiro Barbosa ${ }^{1}$ \\ Grasiela Piuvezam ${ }^{2}$ \\ Adriana da Fonte Porto Carreiro ${ }^{1}$ \\ Kenio Costa Lima ${ }^{1}$
}

\footnotetext{
${ }^{1}$ Departamento de Odontologia, Centro de Ciências da Saúde, Universidade Federal do Rio Grande do Norte (UFRN). Av. Salgado Filho 1787, Lagoa Nova. 59056-000 Natal RN Brasil. annie medeiros@hotmail.com ${ }^{2}$ Departamento de Saúde Coletiva, Centro de Ciências da Saúde, UFRN. Natal RN Brasil.
}

\begin{abstract}
This article aims to analyze the prevalence and associated factors of TMJ alterations in elderly institutionalized. An cross-sectional study of 1192 elderly institutionalized in Brazil was undertaken. Intra and extra-oral exams were performed and the TMJ was evaluated based on the Oral Health Assessment Form of the WHO (1997). Demographic data and elderly dependence were also collected. The self-perception of the elderly regarding oral health was measured using the Geriatric Oral Health Assessment Index - GOHAI. Data analysis was performed using the Chi-squared test and robust Poisson regression (level of significance of 5\%). The prevalence of TMJ alteration was low compared to adults and was only associated with the state of dependence of the elderly individual (independent had $45.4 \%$ more alterations than dependent individuals), gender (women had $47.4 \%$ more alterations), self-perception of oral health (who evaluated negatively had $65.6 \%$ more alterations) and the need of upper dentures (who needed some kind of upper dentures had $45.8 \%$ more alterations than those who did not). Despite being low, the presence of alterations in the TMJ was more frequent in elderly independent, women, who evaluated negatively oral health and need some kind of upper dentures.
\end{abstract}

Key words Temporomandibular joint, Aged, Institutionalization
Resumo O objetivo deste artigo é avaliar a prevalência e os fatores associados a alterações na ATM em idosos institucionalizados. Estudo observacional e transversal, conduzido em 1.192 idosos brasileiros. Foram realizados exames intra e extraoral, baseados na Ficha de Avaliação da OMS (1997). Dados demográficos e nível de dependência também foram coletados. A autopercepção do idoso quanto à saúde bucal foi obtida através do GOHAI (Geriatric Oral Health Assessment Index). Na análise dos dados foram usados o teste do Qui-quadrado e a Regressão robusta de Poisson (nível de significância de 5\%). A presença de alguma alteração na ATM foi pouco prevalente quando comparada a dos adultos, e esteve associada à condição de dependência do idoso (os independentes tiveram $45,4 \%$ mais alterações do que os dependentes), ao sexo (mulheres tiveram 47,4\% mais alterações), à autopercepção de saúde bucal (quem avaliou negativamente teve $65,6 \%$ mais alterações) e à necessidade de prótese (PT) superior (quem necessita de algum tipo de PT superior teve 45,8\%). Apesar de ter sido baixa, a presença de alterações na ATM esteve mais frequente em idosos independentes, do sexo feminino, que avaliaram negativamente a saúde bucal e que necessitam de algum tipo de PT superior.

Palavras-chave Articulação temporomandibular, Idoso, Saúde do idoso institucionalizado, Institucionalização 


\section{Introduction}

The jaw is joined to the base of the cranium by the temporomandibular joint (TMJ), which is responsible for the translational and rotational motion of the jaw during the actions of speaking and chewing ${ }^{1}$.

Initiating, contributing and perpetuating factors can lead to alterations in the TMJ, which can cause the functional imbalance of the organism, affect the masticatory musculature and adjacent structures ${ }^{2,3}$, and is characterized as temporomandibular disorder (TMD). This can be identified by a series of signs and symptoms, such as muscular pain or pain in the TMJ, joint noises and restriction, diversion or deflection during the movement of the mouth opening ${ }^{3}$.

A number of studies have found that multiple factors can lead to the development of this disorder and that it is therefore caused by an association of psychological, structural and behavioral factors $^{2,4}$.

The percentage of the population with some form of TMD is between 40 and 60\% $\%^{4,5}$. According to Fonseca et al. ${ }^{6}$, it was estimated that in Brazil, there are approximately six million individuals with signs and symptoms of TMD. However, the current prevalence of the condition among the population is the subject of debate, due to the low homogeneity of criteria used for the study of different groups ${ }^{4}$. Pereira Júnior et al. ${ }^{7}$, in a review of epidemiological factors, concluded that the prevalence of TMD is low among children, increases among teenagers and adults, and decreases after 45 years of age, being rare among the elderly 5 .

The elderly in Brazil, similar to many countries in the world, is currently the proportionally fastest growing segment of the population, which demands attention for care services ${ }^{8}$. In relation to oral health, root caries, periodontal disease and the high degree of edentulism represent the major problems ${ }^{2,8}$. The high toothlessness rates is considered a worldwide public health issue 9 . The edentulism can generate a collapse in the stomatognathic system, orthopedic instability of TMJ and physical and psychological problems associated with changes in the maxillomandibular relationship, induced during the confeccion of dentures by dentists ${ }^{2,10,11}$. That serve as contributing factors to the development of TMJ alterations ${ }^{2,10,11}$.

Studies evaluating the prevalence of signs and symptoms of TMJ alterations in the elderly, whether institutionalized or not, are few and showed conflicting results regarding prevalence and associated factors ${ }^{5,7,10,11}$. This is due mainly to the different types of instruments used to assess prevalence, which vary widely between studies, as well as regional differences, and the fact that many studies were performed in a single center with a limited sample.

As the elderly have a high tooth loss and, in most cases, have no access to dentures ${ }^{9}$, it is possible that they have alterations in TMJ. Thus, the aim of the present study was to evaluate the prevalence and the factors associated with the signs and symptoms suggestive of temporomandibular joint alterations in elderly institutionalized Brazilians.

\section{Methodology}

The research was conducted following approval from the local Ethics in Research authority. An observational, transversal, multicenter study was conducted in 36 long-term care facilities (LTCF) for the elderly, registered with the Health Inspection Department, in 11 randomly chosen medium and large sized municipalities from the five geographic regions of Brazil (North, Northeast, South, Southeast, and Midwest).

Two cities were randomly drawn from each region, obeying two inclusion criteria: 1 ) municipalities with more than 100,000 inhabitants, according to the Population Projection List of Geography and Statistics Brazilian Institute (IBGE, 2004) for 2005; and 2) municipalities with an elderly population greater or equal to the median found in each geographic region. The LTCF studied were legally registered private and philanthropic entities.

Eligibility criteria for the elderly participants were 1) being institutionalized and 2) being present at the LTCF during the data collection period. So, all elderly individuals aged 60 years or more (in accordance with the legal guidelines of the National Health Policy for Older Persons 2006) were selected ${ }^{12}$.

The elderly individuals underwent an assessment using the Oral Health Assessment Forms recommended by the $\mathrm{WHO}^{13}$, which included the following sections: identifying information about the survey, other general information (name, gender, age, ethnic group, occupation, geographic location and type of locality), extra-oral examination, assessment of temporomandibular joint. The intraoral examination evaluated dental caries and need of treatment, using the DMFT in- 
dex, edentulism and functional edentulism (less than 20 teeth in the mouth), the use and need of dentures, according to WHO criteria ${ }^{13}$.

For the evaluation of the temporomandibular joint (TMJ) the following criteria were analyzed: symptoms (when the patient reported occurrence of cracking, pain, difficulty opening or closing the jaw, once or more per week) and signs (occurrence of cracking, tenderness or reduced mobility of the jaw). Cracking, in one or both TMJ, was defined as an audible sharp sound or palpation. The tenderness of the anterior temporal and/ or masseter on one or both sides, was registered only if the palpation triggered, spontaneously, a reflex of withdrawal or a complaint of pain, and reduced mobility of the jaw was identified when the mouth opening was less than $30 \mathrm{~mm}^{13}$.

The doctors of each LTCF examined the elderly individuals in order to diagnose if they had the cognitive ability to respond to questionnaires, based in a mental evaluation. Those able to respond cognitively responded to the GOHAI (Geriatric Oral Health Assessment Index) questionnaire developed by Atchinson \& Dolan ${ }^{14}$, in 1990 , in order to evaluate the perception of the elderly regarding their oral health. This index is composed of twelve items which consist of information regarding the influences of oral health problems in three dimensions: physical (chewing, swallowing and speech), psychological (social limitations caused by oral health, appearance of teeth, concerns about teeth, gums, or prostheses), and pain or discomfort ${ }^{14}$. Its outcome was categorized as positive (31-36 points) and negative (0-30 points $)^{15}$. The elderly were also evaluated for their dependency status as per clinical diagnosis of the LSIE doctor and were classified as dependent or independent, related to the ability to perform certain daily activities.

Data collection was carried out by five calibrated dentists with Kappa values between 0.71 and 0.89 and the tests were performed in the LTCF environments with natural light. A clinical dental mirror and periodontal probe recommended by the WHO were used for periodontal examinations.

\section{Statistical analysis}

Statistical analysis was conducted using the STATA 10.0 program (Stata Corp., College Station, TX, USA). Data was described using frequency, percentages and means, and standard deviations. In order to find association between the independent variables and the dependent variable "TMJ Alteration" (symptom, sensitivity, cracking or reduced mouth opening), the Chisquared test with continuity correction for a significance level of $5 \%$ was used.

Two multivariate analyses (robust Poisson regression) were used. In one, the association between the independent variables with a value $p<0.20$ and the dependent variable ("Presence of TMJ Alteration") was analyzed, in which the sample corresponded to 582 individuals who were cognitively able to respond to the GOHAI questionnaire. A second analysis was performed with these same variables, without self-perception of oral health, which allowed the multiple analysis to consider the total number of elderly individuals $(\mathrm{n}=1,158)$.

\section{Results}

The resident population at the LTCF during the study period numbered 1412 individuals. Of these, $1192(84.4 \%)$ took part in this investigation, $587(49.2 \%)$ of whom presented with cognitive conditions when responding to the GOHAI, according to the clinical diagnosis made by LTCF doctors.

The mean age of the elderly persons was 76.26 years $( \pm 9.8)$. The majority of the individuals were female, resided in nonprofit LTCF (Long Term Care Facilities) for the elderly and were diagnosed as dependent (Table 1). In relation to self-perception of oral health, $75 \%$ of the elderly persons who responded to the GOHAI $(49.2 \%$ of the total sample) presented a positive evaluation and $25 \%$ negative, while the DMF index (Number of decayed, missing or filled teeth) was high, as was the "missing teeth" component (Table 1).

Of the total of elderly persons enrolled in the study, there was a loss of data of 34 individuals, approximately $2.8 \%$ of the sample, due to the refusal of the same to undergo an extra or intraoral exam. In relation to evaluation of the temporomandibular joint (TMJ), edentulism and the use and need for dentures, the sample included 1,158 individuals.

The majority of elderly individuals had either functional $(87.6 \%)$ or total edentulism $(58.6 \%)$. Less than half of elderly individuals used some type of upper $(38.6 \%)$ or lower $(20.8 \%)$ dentures, whether satisfactory or not. The need for prosthesis was high for upper $(61.8 \%)$ and lower (78.7\%) dentures.

When analyzed separately, the criteria used for assessing the TMJ showed a low prevalence 
of alterations in the group studied. As such, these were grouped into a single variable (Any TMJ alteration) in order to allow a better analysis of the relationship between the presence of any of these changes and the associated factors (Figure 1).

Table 2 displays the results of the analysis between the dependent variable "Any TMJ alter- ation" and the independent variables, which represented the associated factors.

The analysis of the effect of the independent variables on the dependent showed that the only significant association was between the condition of dependency, self-evaluated oral health, gender and need for upper dentures. Independent elder-

Table 1. Distribution of elderly persons by gender, type of LTCF, state of dependence of elderly person and dental condition.

\begin{tabular}{|c|c|c|c|}
\hline & Variables & $\mathbf{n}$ & $\%$ \\
\hline \multicolumn{4}{|l|}{ Gender } \\
\hline & Male & 554 & 46.5 \\
\hline & Female & 638 & 53.5 \\
\hline \multicolumn{4}{|l|}{ LTCF } \\
\hline & Profit & 160 & 13.9 \\
\hline & Non-profit & 998 & 86.1 \\
\hline \multicolumn{4}{|c|}{ Level of dependence of elderly person } \\
\hline & Independent & 469 & 40.5 \\
\hline & Dependent & 689 & 59.5 \\
\hline \multicolumn{2}{|c|}{ DMFT and components } & Mean & $\mathrm{SD}$ \\
\hline & DMFT Index & 29.4 & 4.927 \\
\hline & Number of intact teeth & 2.44 & 4.770 \\
\hline & Number of decayed teeth & 1.21 & 2.689 \\
\hline & Number of decayed and filled teeth & 0.05 & 0.310 \\
\hline & Number of filled teeth & 0.29 & 1.180 \\
\hline & Number of missing teeth & 27.8 & 6.791 \\
\hline & Number of teeth present & 3.99 & 6.637 \\
\hline & Total number of decayed teeth (decayed + filled cavities) & 1.26 & 2.729 \\
\hline
\end{tabular}

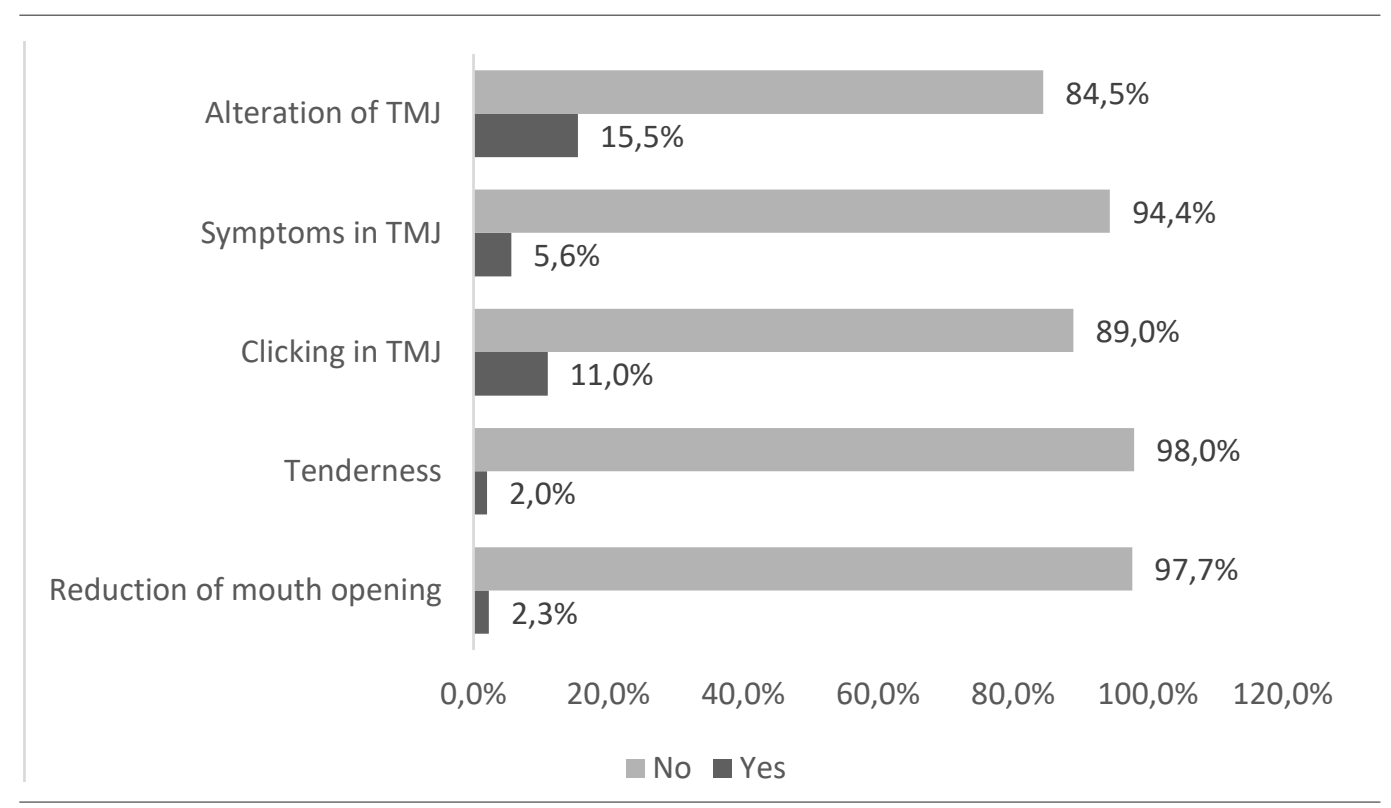

Figure 1. Distribution of TMJ alterations among elderly persons, in terms of categorized variables (Symptom, Sensitivity, Clicking or Reduced mouth opening) and discriminated variables. 
Table 2. Bivariate analysis of variable "presence of TMJ alteration" related to variables independents of study.

\begin{tabular}{|c|c|c|c|c|}
\hline \multirow[b]{2}{*}{ Variables } & \multicolumn{4}{|c|}{ TMJ alteration } \\
\hline & $\begin{array}{c}\text { No } \\
\text { n (\%) }\end{array}$ & $\begin{array}{c}\text { Yes } \\
\text { n (\%) }\end{array}$ & $\mathbf{p}$ & PR (CI 95\%) \\
\hline \multicolumn{5}{|l|}{ General data } \\
\hline \multicolumn{5}{|l|}{ Gender } \\
\hline Male & $469(86.2)$ & $75(13.8)$ & 0.162 & 1.229 \\
\hline Female & $510(83.1)$ & $104(16.9)$ & & $(0.935-1.615)$ \\
\hline \multicolumn{5}{|l|}{ Age } \\
\hline 60 to 77 years & $518(83.1)$ & $105(16.9)$ & 0.181 & 0.821 \\
\hline 78 years or more & $461(86.2)$ & $74(13.8)$ & & $(0.624-1.080)$ \\
\hline \multicolumn{5}{|l|}{ Type of LTCF } \\
\hline Profit & $148(92.5)$ & $12(7.5)$ & 0.004 & 2.231 \\
\hline Non-profit & $831(83.3)$ & $167(16.7)$ & & $(1.273-3.912)$ \\
\hline \multicolumn{5}{|l|}{ Level of dependence } \\
\hline Independent & $370(78.9)$ & $99(21.1)$ & $<0.001$ & 0.550 \\
\hline Dependent & $609(88.4)$ & $80(11.6)$ & & $(0.420-0.721)$ \\
\hline \multicolumn{5}{|l|}{ Self-perception of oral health } \\
\hline Positive evaluation (31 to 36 ) & $360(82.9)$ & $74(17.1)$ & 0.002 & 1.739 \\
\hline Negative evaluation ( 0 to 30 ) & $102(70.3)$ & $43(29.7)$ & & $(1.256-2.408)$ \\
\hline \multicolumn{5}{|l|}{ Oral health condition } \\
\hline \multicolumn{5}{|l|}{ Presence of edentulism } \\
\hline Non-edentulous & $409(85.0)$ & $72(15.0)$ & 0.760 & 1.010 \\
\hline Edentulous & $570(84.2)$ & $107(15.8)$ & & $(0.961-1.061)$ \\
\hline \multicolumn{5}{|l|}{ Functional edentulism } \\
\hline Non-functionally edentulous & $117(81.8)$ & $26(18.2)$ & 0.401 & 0.963 \\
\hline Functional edentulism & $862(84.9)$ & $153(15.1)$ & & $(0.888-1.045)$ \\
\hline \multicolumn{5}{|l|}{ Use of upper dentures } \\
\hline Absent & $590(83.8)$ & $114(16.2)$ & 0.607 & 0.978 \\
\hline Present & $389(85.7)$ & $65(14.3)$ & & $(0.931-1.028)$ \\
\hline \multicolumn{5}{|l|}{ Use of lower dentures } \\
\hline Absent & $766(83.9)$ & $147(16.1)$ & 0.285 & 0.965 \\
\hline Present & $213(86.9)$ & $32(13.1)$ & & $(0.912-1.021)$ \\
\hline \multicolumn{5}{|l|}{ Need of upper dentures } \\
\hline Not needed & $390(86.9)$ & $59(13.1)$ & 0.098 & 1.288 \\
\hline Some form of denture needed & $589(83.1)$ & $120(16.9)$ & & $(0.965-1.719)$ \\
\hline \multicolumn{5}{|l|}{ Need of Lower dentures } \\
\hline Not needed & $218(87.2)$ & $32(12.8)$ & 0.225 & 1.040 \\
\hline Some form of denture needed & $761(83.8)$ & $147(16.2)$ & & $(0.984-1.100)$ \\
\hline
\end{tabular}

ly individuals had $45.4 \%$ more alterations than dependent individuals. Elderly who negatively evaluated their oral health had $65.6 \%$ more alterations than those who evaluated oral health positively. Women had $47.4 \%$ more alterations than men and those who needed some kind of upper dentures had $45.8 \%$ more alterations than those who did not need dentures (Tables 3 and 4).

No other variable objectively related to the condition of oral health showed significant association with the presence of TMJ alterations.

\section{Discussion}

The purpose of the present study was to evaluate the prevalence and the factors associated with the signs and symptoms suggestive of temporomandibular joint alterations in elderly institutionalized Brazilians. The results show a low prevalence of temporomandibular joint (TMJ) alterations and that the main factors associated with the presence of alterations (reported by the patients, tenderness, clicking, or reduced mouth opening) 
Table 3. Multivariate analysis of variable "presence of TMJ alteration" related to variables "gender", "age", "type of LTCF", "level of dependence of elderly person", "self-perception of oral health" and "need of upper dentures".

\begin{tabular}{|c|c|c|c|c|c|}
\hline \multirow[b]{2}{*}{ Variables } & \multicolumn{5}{|c|}{ TMJ alteration } \\
\hline & $\begin{array}{c}\text { Yes } \\
\mathbf{n}(\%)\end{array}$ & p & PR (CI 95\%) & $\mathbf{p}$ & $\begin{array}{c}\text { PR } \\
\text { (CI 95\%) }\end{array}$ \\
\hline \multicolumn{6}{|l|}{ Gender } \\
\hline Male & $57(19.0)$ & 0.453 & 1.032 & 0.148 & 1.285 \\
\hline Female & $60(21.5)$ & & $(0.950-1.120)$ & & $(0.915-1.805)$ \\
\hline \multicolumn{6}{|l|}{ Age } \\
\hline 60 to 77 years & $79(22.1)$ & 0.144 & 0.940 & 0.177 & 0.789 \\
\hline 78 years or more & $38(17.1)$ & & $(0.866-1.019)$ & & $(0.560-1.113)$ \\
\hline \multicolumn{6}{|l|}{ Type de LTCF } \\
\hline Profit & $2(5.7)$ & 0.028 & 1.196 & 0.100 & 3.129 \\
\hline Non-profit & $115(21.1)$ & & $(1.090-1.311)$ & & $(0.804-12.178)$ \\
\hline \multicolumn{6}{|l|}{ Level of dependence } \\
\hline Independent & $97(22.6)$ & 0.015 & 0.893 & 0.024 & 0.606 \\
\hline Dependent & $20(13.3)$ & & $(0.824-0.968)$ & & $(0.392-0.937)$ \\
\hline \multicolumn{6}{|l|}{ Self-perception of oral health } \\
\hline Positive evaluation (31 to 36 ) & $74(17.1)$ & 0.001 & 1.179 & 0.002 & 1.656 \\
\hline Negative evaluation ( 0 to 30 ) & $43(29.7)$ & & $(1.052-1.322)$ & & $(1.201-2.284)$ \\
\hline \multicolumn{6}{|l|}{ Need of upper dentures } \\
\hline Not needed & $45(17.5)$ & 0.149 & 1.062 & 0.164 & 1.284 \\
\hline Need of dentures & $72(22.4)$ & & $(0.980-1.152)$ & & $(0.903-1.825)$ \\
\hline
\end{tabular}

Model adjustment $\left(\chi^{2}\right): p=0.808$

Table 4. Multivariate analysis of variable "presence of TMJ alteration" related to variables "gender", "age", "type of LTCF", "level of dependence of elderly person" and "need of upper dentures".

\begin{tabular}{|c|c|c|c|c|c|}
\hline \multirow[b]{2}{*}{ Variables } & \multicolumn{5}{|c|}{ TMJ alteration } \\
\hline & $\begin{array}{c}\text { Yes } \\
\text { n (\%) }\end{array}$ & $\mathbf{p}$ & PR (CI 95\%) & $\mathbf{p}$ & $\begin{array}{c}\text { PR } \\
\text { (CI 95\%) }\end{array}$ \\
\hline \multicolumn{6}{|l|}{ Gender } \\
\hline Male & $75(13.8)$ & 0.162 & 1.229 & 0.006 & 1.474 \\
\hline Female & $104(16.9)$ & & $(0.935-1.615)$ & & $(1.117-1.945)$ \\
\hline \multicolumn{6}{|l|}{ Age } \\
\hline 60 to 77 years & $105(16.9)$ & 0.181 & 0.821 & 0.417 & 0.894 \\
\hline 78 years or more & $74(13.8)$ & & $(0.624-1.080)$ & & $(0.682-1.172)$ \\
\hline \multicolumn{6}{|l|}{ Type of LTCF } \\
\hline Profit & $12(7.5)$ & 0.004 & 2.231 & 0.060 & 1.732 \\
\hline Non-profit & $167(16.7)$ & & $(1.273-3.912)$ & & $(0.985-3.044)$ \\
\hline \multicolumn{6}{|l|}{ Level of dependence } \\
\hline Independent & $99(21.1)$ & $<0.001$ & 0.550 & $<0.001$ & 0.546 \\
\hline Dependent & $80(11.6)$ & & $(0.420-0.721)$ & & $(0.416-0.717)$ \\
\hline \multicolumn{6}{|l|}{ Need of upper dentures } \\
\hline Not needed & $59(13.1)$ & 0.098 & 1.288 & 0.011 & 1.458 \\
\hline Need of prosthesis & $120(16.9)$ & & $(0.965-1.719)$ & & $(1.090-1.951)$ \\
\hline
\end{tabular}

Model adjustment $\left(\chi^{2}\right): p=0.848$

correspond, principally, to factors that indirectly assess the oral health of the individuals. Tooth loss and need for prosthesis were not associated with the presence of alterations in TMJ.
In relation to the low prevalence, when compared to prevalence in adults, other studies present similar results ${ }^{11,16,17}$. Schmitter et al. ${ }^{16}$ evaluating the presence of different symptoms 
of Temporomandibular Disorder (TMD) in a group of institutionalized elderly persons in Germany, used the RDC/TMD (Research Diagnostic Criteria for Temporomandibular Disorders). The results showed that none of the elderly persons suffered from pain in the TMJ or during mouth opening or closing movements, however, 38\% had joint sounds. Johansson et al. ${ }^{18}$, in 2006, evaluating the prevalence of signs and symptoms of TMD among 6,236 elderly persons, found different results. In this study, $44.7 \%$ of individuals suffered from pain in the TMJ and $51.1 \%$ had difficulty in mouth opening.

These studies show that there is still inconsistency as to the findings regarding the prevalence of signs and symptoms in elderly persons with TMD. The aetiology of TMD is multifactorial including biological characteristics, occlusal disharmony, psycho-emotional disturbance or impaired systemic health. The adaptability of the individual also plays an important role and can be a relevant factor that may explain the low prevalence. So, the human musculoskeletal system is adaptable and can tolerate considerable variation without showing signs of disease or dysfunction ${ }^{19}$.

These findings are also due to the lack of standardization of the questionnaires and methods of assessment used and the size of the selected samples. The RDC/TMD is currently the most widely used questionnaire for assessing TMD, however, due to its length, it makes the data collection process difficult and limits the scope of the study to smaller samples. The present study used the questionnaire recommended by the WHO (1997) and sought a full assessment of the oral health status of the individual being studied, linking general and socioeconomic data to the physical examination, providing wide scope and applicability ${ }^{13}$.

In multivariate analysis of the number of subjects who responded to the GOHAI ( $\mathrm{n}=$ 582), an alteration in TMJ was only significantly associated with the condition of dependency of the elderly person and self-evaluation of oral health status. An independent elderly individual who negatively evaluates their oral health is more likely to have experienced a TMJ alteration.

Of the $49.2 \%$ of seniors who responded to the GOHAI, $75 \%$ had a positive perception of their oral health, which is in agreement with other studies ${ }^{20,21}$. Studies have shown that there is a paradox between the self-perception of oral health by institutionalized elderly persons. Objective evaluation reveals a poor condition of oral health, while seniors evaluate their own oral health as good or excellent $t^{17,21,22}$. The authors hypothesize that these results can be associated with the influence of social and cultural factors ${ }^{21,22}$.

In the analysis of the present study, negative valuation of oral health status was low, however, in multivariate analysis, this was significantly associated with the presence of an alteration of the TMJ. This is perhaps because elderly persons who negatively evaluate their oral health are those that have more teeth or use dentures, and in most cases, both are in poor condition, generating complaints and reflecting an unsatisfactory health condition ${ }^{21,22}$.

In aetiology of TMJ disorders, stress and emotional component are two important contributing factors ${ }^{10,19}$. When they are present and associated with a low adaptability of the individual, they can contribute to the development of signs and symptoms of joint dysfunction ${ }^{19}$. Despite not being the object of this research, it is suggested that there may be an association between negative assessment of oral health condition and these two factors. This relationship could contribute to the development of alterations in TMJ and explain the results. More specific studies are needed to assess this possible relationship.

Another significant variable that was strongly associated with the presence of alteration of the TMJ was the degree of dependency of the elderly person. Dependency is considered a serious health problem that interferes with the quality of life of both the caregiver and the elderly person, who needs help to perform basic activities of daily living, such as self-care, including oral hygiene ${ }^{23,24}$.

Therefore, the significant association of the independence of elderly persons with the presence of an alteration of the TMJ can be explained by the fact that independent elderly persons still use dentures (whether satisfactory or not), perform their own oral hygiene care and are conscious of their oral health condition, whether it is good or bad. In certain situations in LTCFs, the dentures of totally dependent elderly individuals are removed by caregivers to reduce the care provided to the elderly, such as oral hygiene.

The analysis of the total number of elderly individuals that took place in the present study revealed that the variables most associated with the presence of some kind of alteration in the TMJ were gender, and the need of some form of upper denture.

The studied population was elderly, with an average age of 76.26 years. Lopes et al. ${ }^{25}$ and Vi- 
torino et al. ${ }^{26}$ reported a similar mean of 75 and 76.5 years, respectively, as the authors see advanced age as a strong predictor for institutionalization.

There was also a greater prevalence of institutionalized female elderly persons, and such a result may be attributed to the fact that the life expectancy of the female is greater than that of the male ${ }^{22}$. Abud et al. ${ }^{17}$, in 2009, assessed the prevalence of TMD in institutionalized elderly persons in São José dos Campos, Brazil. The results showed a higher prevalence of symptoms of TMD among women, corroborating the findings of other studies ${ }^{5,10,27}$. In order to explain this phenomenon, Martins et $\mathrm{al}^{5}$, reported that one of the reasons for these findings is the fact that women present an unfavorable self-assessment of their oral health condition, referring more often to psychological problems and morbidities.

The "need of upper denture" is a variable that reflects the presence of some kind of edentulous space that has not been rehabilitated or has been rehabilitated in an unsatisfactory manner, and was significantly associated with the presence of an alteration of the TMJ.

Dallanora et al. ${ }^{10}$, in 2012, used the Helkimo index and a personalized questionnaire to evaluate the prevalence of TMD in 127 residents of Luzerna/SC, who complied with the inclusion criteria of using full upper dentures, of which 113 were elderly $(89 \%)$. The results showed a prevalence of TMD of $55.12 \%$, with those individuals that used the same dentures for a period of more than 10 years having more signs and symptoms of TMD.

Following the same idea, in 2013, Sipila et al. ${ }^{27}$ analyzed 6,316 people in Finland, evaluating signs and symptoms of TMD and associated factors such as use, condition of removable dentures and the need of repair of the same. Of these individuals, 1,457 were elderly. The results showed a low prevalence of TMD in the elderly, but edentulism, use of full dentures and poor condition of the denture (older than 5 years) were negatively associated with pain in the TMJ and chewing muscles, as well as the presence of joint sounds. The authors suggest that the problems in the use of prosthesis may predispose to TMD problems. However, it is unclear how.
A limitation of this study was not using RDC/ TMD criteria. However, due to the high number of patients included and the length of the questionnaire, the collection of data would be impractical. The WHO criteria was used because it is internationally validated, be more concise and applicable in epidemiological studies.

Therefore, with this study, it could be perceived that the prevalence of signs and symptoms of alterations in the TMJ, as found by other authors, is low in institutionalized elderly persons and that female, dependent, elderly individuals, who have a negative perception of their oral health and require some type of upper dentures, exhibit more alterations of the temporomandibular joint. Despite these results, should be considered the individuality of the elderly and the regional and cultural characteristics which may influence the findings. The aetiology of the TMJ disorder is multifactorial and the individual component plays an important role. Furthermore, studies carried out are distinct as the population. Thus, the discussion of the factors associated with TMJ should be made carefully. It is required the implementation of further studies that follow the same methodological design and use similar population groups.

\section{Conclusions}

The present study reflects a scenario in which there is low prevalence of signs and symptoms of alterations of the TMJ in elderly institutionalized persons and that the main factors associated with the presence of alterations of the TMJ correspond, principally, to factors that indirectly assess the oral health of the individuals. As such, more independent female elderly persons, who negatively evaluated their oral health and required some form of upper denture, are classified as suffering from alterations of the temporomandibular joint (TMJ). Psychosocial factors can have a modifying effect on these associations. Thus, strategies to improve the quality of life, to exploring the importance of health care and the need for denture replacement, as prevention of total dental loss, are important to improve oral health and minimize the local risk factors for TMJ alterations. 


\section{Collaborations}

AKB Medeiros worked in intellectual and scientific content of the study; acquisition, interpretation, analysis of data and manuscript writing. FP Barbosa worked in acquisition, interpretation and analysis of data and manuscript writing. $G$ Piuvezam and AFP Carreiro worked in the interpretation and analysis of data, writing and revision of manuscript. KC Lima worked in the conception, design, intellectual and scientific content of the study, interpretation, analysis of data and writing of the manuscript.

\section{References}

1. Alomar X, Medrano J, Cabratosa J, Clavero JA, Lorente M, Serra I, Monill JM, Salvador A. Anatomy of the temporomandibular joint. Semin Ultrasound CT MR 2007; 28(3):170-183.

2. Bontempo KV, Zavanelli RA. Fatores etiológicos correlacionados à desordem temporomandibular em pacientes portadores de próteses totais bimaxilares: uma análise comparativa. RGO 2009; 57(1):65-75.

3. Manfredini D, Piccotti F, Ferronato G, Guarda-Nardini L. Age peaks of different RDC/TMD diagnoses in a patient population. J Dent 2010; 38(5):392-399.

4. Martins RJ, Garbin CAS, Garcia AR, Garbin AJI, Miguel N. Stress levels and quality of sleep in subjects with temporomandibular joint dysfunction. Rev Odonto Ciênc 2010; 25(1):32-36.

5. Martins RJ, Garcia AR, Garbin CAS, Sundefeld MLMM. Relação entre classe socioeconômica e fatores demográficos na ocorrência da disfunção temporomandibular. Cien Saude Colet 2008; 13(2):2089-2096.

6. Fonseca DM, Valle GBAL, Freitas SFT. Diagnóstico pela anamnese da disfunção craniomandibular. RGO 1994; 42(1):23-28

7. Pereira Júnior FJ, Vieira AR, Prado R, Miasato JM. Visão geral das desordens temporomandibulares. Parte I: definição, epidemiologia e etiologia. RGO 2004; 52(2):117-121.

8. Simões ACA, Carvalho DM. A realidade da saúde bucal do idoso no Sudeste brasileiro. Cien Saude Colet 2011; 16(6):2975-2982.

9. Piuvezam G, Lima KC. Factors associated with missing teeth in the Brazilian elderly institutionalised population. Gerodontology 2013; 30(2):141-149.

10. Dallanora AF, Grasel CE, Heine CP, Demarco FF, Pereira-Cenci T, Presta AA, Boscato N. Prevalence of temporomandibular disorders in a population of complete denture wearers. Gerodontology 2012; 29(2):865-869.

11. Santos JF, Marchini L, Campos MS, Damião CF, Cunha VP, Barbosa CM. Symptoms of craniomandibular disorders in elderly Brazilian wearers of complete dentures. Gerodontology 2004; 21(1):51-52.

12. Brasil. Portaria GM no 2.528, de 19 de outubro de 2006 - Política Nacional de Saúde da Pessoa Idosa - PNSI. Diário Oficial da União 2006; 19 out.

13. Organização Mundial da Saúde (OMS). Levantamento epidemiológico básico de saúde bucal: manual de instruções. 4a ed. São Paulo: Editora Santos; 1997.

14. Atchison KA, Dolan TA. Development of the geriatric oral health assessment index. J Dent Educ 1990; 54(11):680-686.

15. Silva DD, Souza MLR, Wada RS. Self-perception and oral health conditions in a elderly population. Cad Saude Publica 2005; 21(4):1251-1259.

16. Schmitter M, Rammelsberg P, Hassel A. The prevalence of signs and symptoms of temporomandibular disorders in very old subjects. J Oral Rehabil 2005; 32(7):467-473.

17. Abud MC, Santos JFF, Cunha VPP, Marchini L. TMD and GOHAI indices of Brazilian institutionalized and community-dwelling elderly. Gerodontology 2009; 26(1):34-39. 
18. Johansson A, Unell L, Carlsson GE, Söderfeldt B, Halling A. Risk factors associated with symptoms of temporomandibular disorders in a population of 50- and 60-year-old subjects. J Oral Rehabil 2006; 33(7):473481.

19. Okeson JP. Tratamento das Desordens Temporomandibulares e Oclusão. 7a ed. Rio de Janeiro: Elsevier; 2013.

20. Martins AMEB, Barreto SM, Pordeus IA. Objective and subjective factors related to self-rated oral health among elderly. Rep Public Health 2009; 25(2):421-434.

21. Piuvezam G, Lima KC. Self-perceived oral health status in institutionalized elderly in Brazil. Arch Gerontol Geriatr 2012; 55(1):5-11.

22. Melo LA, Sousa MM, Medeiros AKB, Carreiro AFP, Lima KC. Factors associated with negative self-perception of oral health among institutionalized elderly individuals. Cien Saude Colet 2016; 21(11):3339-3346.

23. Marinho LM, Vieira MA, Costa SM, Andrade JMO. Grau de dependência de idosos residentes em instituições de longa permanência. Rev Gaúcha Enferm 2013; 34(1):104-110.

24. Souza EHA, Barbosa MBCB, Oliveira PAP, Espíndola J, Gonçalves KJ. Impact of oral health in the daily life of institutionalized and non institutionalized elder in the city of Recife (PE, Brazil). Cien Saude Colet 2010; 15(6):2955-2964.

25. Lopes MC, Oliveira VMB, Flório FM. Oral condition, habits and treatment necessity of institutionalized elders in Araras (SP, Brazil). Cien Saude Colet 2010; 15(6):2949-2954.

26. Vitorino LM, Paskulin LMG, Vianna LAC. Qualidade de vida de idosos da comunidade e de instituições de longa permanência: estudo comparativo. Rev. Latino -Am. Enfermagem 2013; 21(n. esp.):3-11.

27. Sipila K, Näpänkangas R, Könönen M, Alanen P, Suominen AL. The role of dental loss and denture status on clinical signs of temporomandibular disorders. J Oral Rehabil 2013; 40(1):15-23.

Artigo apresentado em 13/03/2017

Aprovado em 01/06/2017

Versão final apresentada em 03/06/2017 